\title{
EDUCAÇÃO, PODER E AUTORIDADE DOCENTE TRAMAS E SENTIDOS NA CONTEMPORANEIDADE
}

\author{
EDUCATION, POWERAND TEACHING AUTHORITY: PLOTS AND SENSES IN \\ CONTEMPORANEITY \\ EDUCACIÓN, PODER Y AUTORIDAD DOCENTE: TRAMAS Y SENTIDOS EN LA \\ CONTEMPORANEIDAD
}

\begin{abstract}
Jorge Teles
Doutorando do Programa de Pós-Graduação em Educação da Universidade Federal Fluminense. Especialista em Políticas Públicas e Gestão Governamental* | Brasil

E-mail: Jl.teles@yahoo.com.br

André Lázaro

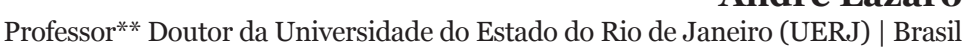
E-mail: andrelflazaro@gmail.com

REVISTA PEDAGÓGICA

Revista do Programa de Pós-graduação em Educação da Unochapecó | ISSN 1984-1566

Universidade Comunitária da Região de Chapecó | Chapecó-SC, Brasil

Como referenciar este artigo: TELES, J. LÁZARO, A. Educação, poder e autoridade docente: tramas e sentidos na contemporaneidade. Revista Pedagógica, Chapecó, v.16, n.33, p. 307 - 323, Jul./Dez. 2014.
\end{abstract}

\begin{abstract}
RESUMO: $O$ artigo procura abordar as questões relativas à crise na autoridade docente constatadas na contemporaneidade a partir da discussão maior sobre crise de poder na sociedade e sobre o lugar da educação no sistema mais amplo das relações humanas. A partir da problematização do poder e das imbricações entre educação e poder, a questão da autoridade docente é analisada, tendo como base pesquisa com professores. Entendendo as tensões em sala de aula e o ambiente de relações negociadas e de resistências enfrentadas dentro e fora da escola pela função docente, confirma-se que a visão do senso comum sobre crise na autoridade do professor está na superfície de fenômenos muito mais complexos. O artigo aponta para a necessidade de abordagens multidisciplinares para ampliação e aprofundamento das discussões sobre educação e poder nas sociedades contemporâneas.
\end{abstract}

PALAVRAS-CHAVE: Educação. Poder. Autoridade. Docência.

\begin{abstract}
The article aims to address issues relating to the crisis in teaching authority found in contemporary, considering the main discussion of power crisis in society and the place of education in the wider system of human relations. From the questioning of power and imbrications between education and power, the issue of teaching authority is analyzed, based on research with professors. Understanding the tensions in the classroom and theresistances and negotiated relationships that exist in the environment within and outside the school for the teaching profession, it corroborates that the common sense view on the crisis in the teacher's authority is on the surface of much more complex phenomena. The article points to the need for multidisciplinary approaches to broadening and deepening the discussion on education and power in contemporary societies.
\end{abstract}

KEYWORDS: Education. Power. Authority. Teaching. 
*Coordenou programas e políticas de Educação dejovens e Adultos e de Livro e Leituranos Ministérios da Educação e da Cultura.

** Foi Secretário da Secretaria de Educação Continuada, Alfabetização e Diversidade do MEC (2007 a 2010).

\section{INTRODUÇÃO}

O objetivo deste artigo é refletir a respeito de algumas questões que se destacam no debate sobre autoridade docente, a partir de uma contextualização maior, onde se discute a própria relação entre educação e poder, a partir de análise de algumas produções intelectuais oriundas de diferentes áreas do saber. Cabe destacar que, diante da complexidade do tema, importa colocar em diálogo diferentes pontos de vista, a partir de vários ângulos epistemológicos. Esta multiplicidade de olhares tenta auxiliar o entendimento mais holístico de um fenômeno tão enunciado contemporaneamente: a crise na educação. Enfocando um aspecto específico dos múltiplos discursos sobre o que seria esta crise na educação, a questão da autoridade docente é posta em evidência, apontando para um fenômeno mais amplo do que a simples relação professor-aluno em sala de aula.

Tomando como referência o debate sobre o que é o poder, o artigo parte da problematização sobre o tema realizada por Mario Stoppino e por Michel Foucault envolvendo olhares da Ciência Política e da Filosofia, respectivamente. Trazendo como contraponto outra corrente filosófica, por meio de Hannah Arendt, o artigo dá voz a uma corrente mais presente nas diversas mídias e que permeia muito do que se argumenta mediante o senso comum. Em uma posição crítica ao senso comum e já trazendo elementos da chamada crise da educação contemporânea, nova contra-argumentação é realizada a partir do posicionamento críticode um educador, Vitor Paro,e da sociologia, com Pierre Bourdieu. Para melhor contextualizar e realmente imergir no que acontece dentro do ambiente escolar, em profundo diálogo com os sujeitos que exercem a função docente, reconhecendo suas vozes, o artigo aprofunda o debate a partir de pesquisa com professores em exercício realizada pelos pesquisadores da área de psicologia da educação Marcelo Pereira, Bárbara Paulino e Raquel Franco.

\section{EDUCAÇÃO ENQUANTO PODER}

Em primeiro lugar, cabe entender o que significa o próprio termo poder. Mario Stoppino (2007b) começa definindo poder como capacidade ou possibilidade de agir, de produzir efeitos, que, em termos sociais, traduzse como poder do homem sobre o homem. Portanto, poder, quando se refere ao social, é sempre relação entre pessoas. Ele sempre exigirá os que o exercem e aqueles sobre quem ele é exercido. Esse exercício sempre está relacionado a uma esfera do social, que pode ser mais ou menos ampla e mais ou menos especializada. Ele 
pode ser potencial (uma possibilidade de se induzir o comportamento) ou atual (em ato) - poder efetivamente exercido, comportamento determinado. Quando um indivíduo (ou grupo) tem recursos e habilidade de utilizálos para influenciar o comportamento de outro indivíduo (ou grupo) e este outro se deixa influenciar, adotando o comportamento intencionado pelo primeiro, há uma relação de poder em exercício. Se isto se dá de modo regular, com alta probabilidade de ambas as atitudes ocorrerem continuamente, dá-se o poder estabilizado. Este poder tanto pode se articularàs características pessoais quanto à função do detentor do poder. Quando estas funções estão definidas e coordenadas, dá-se o poder institucionalizado.

O exercício do poder também é influenciado pelas percepções dos indivíduos (imagens sociais do poder) e pelas expectativas dos atores quanto às (re)ações dos demais atores e aos possíveis desdobramentos da situação, e pode se dar de vários modos (persuasão, manipulação, ameaça, punição, recompensa etc.). Estes modos podem gerar uma conflitualidade, seja por conflito entre as vontades dos indivíduos/grupos, ou por um ressentimento pela desigualdade na distribuição dos recursos relacionados ao exercício do poder. O enfrentamento dessa conflitualidade passa por uma série de fatores, inclusive pela mensuração do poder - probabilidade de que o comportamento intentado se verifique, número de indivíduos/grupos submetidos ao poder, esfera onde se exercita este poder, grau de modificação do comportamento dos submetidos a este poder e restrição de outros comportamentos diferentes a esses submetidos. Além disso, devem ser considerados outros fatores, como posição na hierarquia, reputação, participação na tomada de decisão etc.

Michel Foucault (Foucault, 2000) também trabalhará o poder a partir de uma visão social, relacional. O poder para Foucault não é uma coisa, ele é uma prática social constituída historicamente. Ele não existe, mas se configura em relações e práticas. Ele é algo que se exerce, que funciona nas relações.

Foucault não aborda a questão do poder apenas considerando a dimensão política institucionalizada. Ele entende o Estado como uma fonte macro de poder, mas vai enfocar formas de exercício do poder diferentes do Estado, estando articuladas a ele e lhe dando sustentação e eficácia na atuação. Portanto, para ele, as relações de poder possuem dois níveis não concorrentes: exercício macro e micro do poder. Estado e outras instâncias micro são dois âmbitos separados, mas direta e indiretamente imbricados.

O Poder não está localizado em um determinado ponto da estrutura social. Antes, porém, está disseminado por toda esta estrutura. O poder está espraiado pela sociedade e não existe nada que esteja fora dessa rede. Não existe quem detenha o poder e aqueles que não têm poder 
nenhum - o que difere um pouco de algumas colocações de Stoppino. O poder estende sua mecânica por toda a sociedade, capilariza-se, institucionaliza-se, corporifica-se nas técnicas de dominação, penetra no cotidiano, controla os corpos dos indivíduos, atuando no corpo social como micro-poder.Como está enredado em toda a estrutura social, qualquer luta contra o poder não pode ser feita fora deste. As resistências ao exercício do poder também se encontram espalhadas pela estrutura social, de forma móvel, dinâmica, relacional.

Diferindo de algumas colocações de Stoppino (2007b), para Foucault (2000), o poder não pode ser definido como o exercício da repressão, da negação, da imposição de limites, do castigo. Foucault chama a atenção para outra dimensão, positiva, produtiva das relações de poder: a dominação.

Por exemplo, nas sociedades capitalistas, as relações de poder buscam tornar o homem dócil, aumentando sua força econômica em detrimento da força política. Foi desenvolvida uma tecnologia de controle dos corpos: o poder disciplinar. $\mathrm{O}$ exercício deste poder impõe uma relação de utilidade-docilidade ao corpo. Ele envolve a organização do espaço, o controle do tempo, a vigilância total e ininterrupta e a produção de saber, de forma articulada. Para Foucault, um dos mais importantes efeitos desse poder disciplinar é a produção da individualidade, ou seja, essa individualidade é preexistente ao poder enquanto Stoppino (2007b) define poder partindo da individualidade (indivíduo, ator, sujeito etc. que produz ou intenciona uma ação).

Foucault mostra o poder como produtor de saberes: as relações de poder situam os saberes modernos.Saber e poder estão mutuamenteimplicados:

"Não há saber neutro. Todo saber é político."

“ [...] todo saber tem sua gênese em relações de poder."

"Todo ponto de exercício do poder é, ao mesmo tempo, um lugar de formação do saber."

"E, em contrapartida, todo saber assegura o exercício de um poder."

"O saber funciona na sociedade dotado de poder.” (Foucault, 2000, p. XXI-XXII).

Foucault também chama a atenção para asimplicações entre poder, direito e verdade. As relações de poder lançam mão de regras de direito para produzir discursos de verdade. O direito é visto como um dos instrumentos de dominação do poder. Esta dominação é entendida como manifesta de múltiplas formas, na sociedade, entre os sujeitos em 
suas relações recíprocas. Ela se capilariza, ultrapassando os limites do jurídico. Com isto, ela materializa a sujeição, constituindo os sujeitos.

Apesar de haver dominação, os indivíduos não detém o poder. Pelo contrário, o poder passa pelos indivíduos que ele mesmo constituiu. Este tipo de poder constituinte é o poder disciplinar. Ele é múltiplo e é exercido pela vigilância ininterrupta, em um sistema minucioso de coerções materiais e que permite extrair dos corpos tempo e trabalho. Essas disciplinas têm o seu discurso, criam aparelhos de saber e de múltiplos domínios de conhecimento. Esse discurso é o da normatização. Estas normalizações se chocam com o discurso jurídico da soberania, que democratiza a soberania mediante o direito público articulado com a soberania coletiva das sociedades modernas.

Para Michel Foucault (Foucault, 2013), essas disciplinas visam adestrar corpos dóceis. O corpo é dócil quando pode ser analisado, submetido, manipulado, utilizado, transformado e aperfeiçoado. As disciplinas permitem controlar o corpo e suas operações de forma minuciosa e constante, produzindo relações de utilidadedocilidade.

A disciplina distribui os indivíduos no espaço. Por vezes, ela delimita um espaço específico, cercado, mas, o principal é delimitar um espaço celular, imediatamente localizado. Isto se dá visando a vigilância e a produção de maior utilidade. Mas esta localização não é um 'simples pedaço de chão', medido em metros quadrados, mas uma disposição em uma fila, um arranjo, em uma rede de relações. Isto possibilita controlar tanto o trabalho de um indivíduo quanto o de todos simultaneamente.Tratase de por ordem na confusa multidão, a fim de dominála: distribuí-la e analisá-la, controlá-la e conhecê-la. Ela se constitui, por isto, em técnica de poder, ao mesmo tempo em que se configura como processo de saber. Como exemplo, no caso escolar: "Fez funcionar o espaço escolar como uma máquina de ensinar, mas também de vigiar, de hierarquizar, de recompensar." (Foucault, 2013, p. 142).

A disciplina também controla as atividades. $\mathrm{O}$ horário é dividido de forma esmiuçada, em busca de tornar o tempo empregado integralmente útil, de qualidade, do ponto de vista de aplicação e exatidão. $O$ ato passa a ser elaborado do ponto de vista temporal, envolvendo a melhor relação entre cadagesto determinado e a atitude do corpo como um todo. Esta disciplina também controla a relação entre corpo e objeto, determinando a sincronização entre ambos em cada ato. Todo este controle e economia devem ser administrados utilizando o tempo de forma sempre crescente, exaustiva.

A disciplina adiciona e capitaliza o tempo, dividindo sua duração em partes sucessivas ou paralelas, cada uma 
visando um determinado fim, de forma ajustada. Estas sequências devem ser organizadas de acordo com esquema analítico que parte do mais simples e vai se tornando mais complexo, tendo um horizonte delimitado, marcado por um exame que definirá se o indivíduo alcançou o nível previsto, se ele aprendeu como os outros e, ao mesmo tempo, se ele se diferencia desses outros. Estas sequências serão organizadas em séries, e em séries de séries, localizando os indivíduos em um local dessas séries temporais que especifica seu nível e sua categoria. Ou seja, o poder disciplinar articula, controla e garante a utilização produtiva do tempo.

O corpo singular se constitui em um elemento dentro de uma máquina multissegmentar. Esta máquina vai ajustando o tempo de uns aos tempos dos outros, para extrair o máximo de forças e combiná-las em um resultado ótimo. Para tal, faz-se necessário um sistema de comando, no qual a ordem não precise ser explicada, mas, ao ser sinalizada, provoque o comportamento desejado. Por exemplo, a escola se torna uma máquina de aprender, onde cada aluno, cada nível e cada momento são combinados e utilizados no processo geral de ensino, de modo adequado e permanente.

Um dos elementos que compõem a organização desta máquina disciplinar é o exercício. Foucault define exercício como:

[...] a técnica pela qual se impõe aos corpos tarefas ao mesmo tempo repetitivas e diferentes, mas sempre graduadas. Dirigindo o comportamento para um estado terminal, o exercício permite uma perpétua caracterização do indivíduo seja em relação a esse termo, seja em relação aos outros indivíduos, seja em relação a um tipo de percurso. Assim, realiza, na forma da continuidade e da coerção, um crescimento, uma observação, uma qualificação. (Foucault, 2013, p. 155).

O poder disciplinar é um poder que adestra; sua atuação organiza as forças para extrair delas o máximo. $\mathrm{O}$ poder disciplinar fabrica indivíduos e lida com eles como objetos, ao mesmo tempo em que os toma como instrumentos de seu exercício. O sucesso dessa empreitada advém do olhar hierárquico, da sanção normalizadora e do exame. A vigilância hierárquica introduz um elemento que fiscaliza ao mesmo tempo em que faz parte do mecanismo fiscalizado, aumentando sua eficiência. Apesar de ser hierarquizada, ela se espraia por toda a rede de relações, provocando perene fiscalização, inclusive dos próprios fiscais, de forma múltipla, anônima e automática.

"Na essência de todos os sistemas disciplinares, funciona um pequeno mecanismo penal." (Foucault, 
2013, p. 171). As disciplinas estabelecem, no nível micro, infrapenalidades (do tempo, da atividade, da maneira de ser, dos discursos, do corpo, da sexualidade etc.). As punições constituem um conjunto que vai desde castigos físicos até atos mais sutis, como certa indiferença por parte do punidor. Estas punições devem ser aplicadas a tudo que não estiver conforme à regra. Elas abrangem tanto a quebra de um regulamento, quanto a não adequação a uma regularidade (de duração, de tempo ou de aptidão). Como sua função é corretiva, privilegiam o exercício, em um sistema de gratificação-punição, treinamento e correção. Ela gera, assim, um sistema de contabilidade de boas e más ações, que é permanentemente acionado na valoração do indivíduo com verdade. Isto produz um duplo efeito: insere os indivíduos em um sistema de classificação, com consequências para outros ambientes (fora da instituição), e sujeita ao mesmo modelo e dociliza os indivíduos.

"A penalidade perpétua que atravessa todos os pontos e controla todos os instantes das instituições disciplinares compara, diferencia, hierarquiza,homogeniza, exclui. Em uma palavra, ela normaliza." (Foucault, 2013, p. 176) As disciplinas explicitam o poder da norma, enquanto princípio de coerção, homogeneizando ao mesmo tempo em que aponta os desvios e a gradação das diferenças individuais.

O exame reúne em si a hierarquização da vigilância e a normatização da sanção. Ele sujeita o indivíduo, compara-o, classifica-o, expõe-no, estabelecendo um conhecimento, um saber sobre ele, que será utilizado dentro dos mecanismos das relações de poder. Ele formaliza os traços individuais dentro das relações de poder, registrando-os por meio de um sistema de códigos disciplinares. Esta escrita traz a possibilidade de objetivar o indivíduo, para analisá-lo e identificar suas especificidades, mantendo-o sob o controle de um saber que é permanente, ao mesmo tempo em que viabiliza comparações globais, categorizações gerais e a constituição de um sistema comparativo para grupos e populações. Esta capacidade descritiva que transforma cada indivíduo em um caso é um meio de controle e também é um método de dominação.

[...] o exame está no centro dos processos que constituem o indivíduo como efeito e objeto de poder, como efeito e objeto de saber. É ele que, combinando vigilância hierárquica e sanção normalizadora, realiza as grandes funções disciplinares de repartição e classificação, de extração máxima das forças e do tempo, de acumulação genética contínua, de composição ótima das aptidões. Portanto, de fabricação da individualidade celular, orgânica, genética e combinatória. Com ele se ritualizam aquelas disciplinas que se pode caracterizar com uma palavra dizendo que 
são uma modalidade de poder para o qual a diferença individual é pertinente. (Foucault, 2013, p. 184).

Portanto, para Foucault a educação é uma instância disciplinar da sociedade. Para ele, o exercício do poder que se dá na educação e a partir da educação é constitutivo do indivíduo nesta sociedade.

\section{O LUGAR SOCIAL DA EDUCAÇÃO E A CRISE DE PODER}

Hannah Arendt (Arendt, 2001), por sua vez, apesar de abordar a relação entre os indivíduos, terá um olhar diferente sobre o poder (autoridade) e sobre a educação. Em primeiro lugar, ela elabora educação como uma porta de entrada para o mundo, voltada especificamente para crianças. A partir da saída da juventude, o assunto passa a ser político, não mais educacional. Para Arendt, a educação não tem como função individualizar, como em Foucault, mas desenvolver a criança em ser humano.

Arendt (2001) aponta um discurso de crise na educação e procura identificá-lo e analisá-lo. Neste sentido, ela critica três pressupostos. O primeiro pressuposto é de que existe um mundo da criança autônomo, onde se leva em conta o grupo, e não a criança individualmente. Neste mundo, os adultos aparecem apenas para auxiliar o governo pueril. "Ele [o adulto] apenas pode dizer-lhe [para a criança] que faça aquilo que lhe agrada e depois evitar que o pior aconteça." (Arendt, 2001, p. 230). As crianças são banidas do mundo dos adultos e são entregues à própria sorte ou ao grupo, onde sofrem pressões dos próprios pares. Para Arendt, o exercício da autoridade no seio do grupo infantil se dá de modo tirânico, extremamente opressivo. Para a autora, esta severidade do grupo suplanta qualquer tipo de excesso de autoridade de um indivíduo isolado.

O segundo pressuposto é de que a pedagogia forma especialistasemensinarqualquercoisa, independentemente da matéria. O professor não precisa mais dominar uma matéria específica, perdendo assim, na visão de Arendt (2001), sua fonte mais legítima de autoridade, colocando em crise a possibilidade de não ser autoritário e de abrir mão de métodos de compulsão.

O terceiro pressuposto diz respeito ao pragmatismo, à substituição do aprender pelo fazer e do trabalho pelo brincar. A proposta pedagógica em questão seria de não ensinar conhecimentos, mas demonstrar como se constrói o saber, de forma lúdica. Para Arendt, ao proceder desta forma, a educação deixa de preparar a criança para o mundo adulto, além de manter artificialmente as crianças 
o maior tempo possível no nível da primeira infância. Isto contraria, segundo a autora, a própria natureza da infância: temporária, preparação para a fase adulta. Para ela, a criança não é exatamente um ser humano, mas é um ser humano em desenvolvimento.

Para Arendt (2001), estes três pressupostos são a causa da crise na educação atual. Sair da crise é restaurar o ensino: recuperar sua condução com autoridade, retomar o trabalho em detrimento do brinquedo e refocar no currículo, colocando à margem as habilidades extracurriculares.

A educação moderna desconsidera a necessidade da intimidade da criança, que demanda proteção e segurança. Segundo Arendt (2001), essa educação expõe a criança prematuramente à vida pública. Ao promover um mundo autônomo da criança, ela emancipa a criança e a deixa exposta a um mundo público para o qual ela não está preparada.

A escola é uma instituição que atua entre os mundos privado e público. Como espaço de introdução da criança no mundo, a escola deveria introduzi-la aos poucos. Isto deveria ser feito pelo professor, na condição de inserido em um processo de responsabilidade coletiva pelo mundo. Esta postura confere autoridade legítima ao professor: "A qualificação do professor consiste em conhecer o mundo e ser capaz de instruir os outros acerca deste, porém sua autoridade se assenta na responsabilidade que ele assume por este mundo." (Arendt, 2001, p. 239). Neste sentido, segundo a autora, não se pode eliminar a autoridade do professor, como se as crianças fossem oprimidas pelos adultos. A escola deve procurar conservar a criança frente ao mundo.

A crise na autoridade na esfera pública tem consequências sobre a esfera privada. A crise da tradição repercute na educação, gerando crise de autoridade. A crise na educação contrapõe uma escola baseada em autoridade e tradição e um mundo que questiona e solapa ambas. A saída, para Arendt, passa por um isolamento da educação, principalmente da vida pública e política, provocando uma aplicação específica dos conceitos de autoridade e de tradição que lhe sejam pertinentes - sendo que estes não podem ser generalizadamente aplicados ao mundo dos adultos.

A função da escola não é ensinar às crianças a arte de viver, mas ensiná-las como o mundo é. Isto foca o processo educativo na tradição, tornando-o conservador. Esta educação nem deve abandonar as crianças à própria sorte, tampouco se fechar para o novo.

Para Arendt, a perda de autoridade dos pais (adultos) sobre as crianças e dos mestres sobre os alunos repercute em crise de plausibilidade de todas as outras relações autoritárias na sociedade moderna. Cabe destacar que, 
para esta autora, a autoridade é sempre hierárquica e exclui o uso de meios externos de coerção pela força e de persuasão por argumentos. É o reconhecimento do direito e da legitimidade da hierarquia tanto por quem manda quanto por quem obedece que caracteriza a autoridade. Para a autora, esta autoridade está assentada na tradição. Portanto, a crise histórica da tradição repercute em crise de autoridade, em perda da permanência e da segurança do mundo.

Todavia, quanto se reflete sobre autoridade, há de se explorar este conceito por outros ângulos. Por exemplo, Stoppino (2007a) problematiza o conceito de autoridade, compreendendo-o de forma mais diversificada que a de Arendt (2001). Para ele, a autoridade é uma espécie de poder e pode se manifestar na forma de poder estabilizado e institucionalizado, onde os dominados prestam obediência incondicional aos dominadores. Esta concepção não considera possibilidade de persuasão, tal como colocado por Arendt. Mas, para Stoppino, este poder pode ser exercido baseado na legitimidade do poder (como é o caso para Arendt), ou por coerção (possibilidade desconsiderada por Arendt). Stoppino também compreende que ao lado da autoridade estabelecida pode emergir outra autoridade, que, apesar de ser conflituosa com a tradicional, também possui a mesma natureza, ou seja, também se constitui como autoridade.

Dando ênfase à autoridade como poder legítimo, Stoppino (2007a) destaca que esta pressupõe um juízo de valor positivo em relação ao poder - seja em relação ao conteúdo, ao modo como são transmitidas ou à fonte das ordens. Este juízo produz pré-disposição para obediência incondicional, que é periodicamente renovada mediante reafirmação da qualidade da fonte de onde emana esse poder. Isto aponta para a existência de dois lados nas relações de poder que caracterizam a autoridade: o lado de quem manda (expectativa de obediência) e o lado de quem obedece (reconhecimento da legitimidade de quem ordena). Na prática, nem sempre este binômio aparece de forma pura, mas vem matizado com reforços para provocar a obediência - possibilidade de obrigar, punir, aliciar ou premiar. Estes reforços podem inclusive vir de outros indivíduos que estão sujeitos à mesma relação de poder e que exercem pressões laterais para que o indivíduo obedeça.

Segundo Stoppino (2007a), o exercício do poder pode se dar em um contexto onde apenas um dos lados reconheça a legitimidade deste poder em ação. Se esta crença ocorre do lado dos que obedecem, ela confere ao poder um status de autoridade, conferindo-lhe eficácia e estabilidade. Estes efeitos podem ser de tal monta que legitimem inclusive o uso de certos graus de violência por parte dos dominantes. Por outro lado, o poder pode ser apenas aparente ou estar 
assentado em questões psicológicas, e até ser relativo à possibilidade de punição, como, por exemplo, quando os pais se valem dessa possibilidade para dominar sobre os filhos, podendo gerar um respeito e um afeto nos filhos, produzindo uma crença não genuína na autoridade dos pais - aspecto não trabalhado por Arendt (2001).

Quando um dos lados da relação de poder já não mais acredita na legitimidade deste, pode se instalar um profundo conflito, de acordo com Stoppino (2007a). Caso os dominados não mais vejam no dominante um poder legítimo, mas o dominante continuar entendendo desta forma, este dominante persistirá na demanda por obediência e não encontrará eco entre os dominados. Isto gera crise de autoridade e pode conduzir o dominante a lançar mão de outras estratégias de coerção e persuasão. Nestes contextos pode ocorrer o surgimento do autoritarismo. A utilização de violência tende apenas a agravar o conflito. Arendt (2001) tangencia esta questão ao tratar da crise de autoridade advinda da tradição e do naufrágio da estrutura de suporte do exercício do poder constituída na tríade romana: religião, tradição e direito. Todavia, ela não explora a questão do mesmo ponto de vista de Stoppino (2007a), talvez por estar preocupada com a questão da relação de autoridade entre adultos e crianças no ambiente escolar.

Tanto Stoppino (2007a;2007b) quanto Foucault (2000;2013) vão abordar as questões das relações de poder, onde a educação é uma das manifestações de formas dessas relações que também ocorrem em outras áreas da sociedade. Arendt (2001) separa a educação como um espaço diferenciado frente às dinâmicas do poder na sociedade. Ao separar educação e política, perde-se a possibilidade de entender melhor as imbricações entre o espaço educacional e outras áreas da sociedade. A conflituosidade das relações de poder que se dão fora do ambiente escolar impactam este, mas também as relações disciplinares que se dão neste ambiente repercutem sobre o funcionamento de toda a sociedade.

A visão do papel estratégico da instituição disciplinar que é a escola para a reprodução da estrutura social e para a manutenção das relações de poderes constituídas foi explorada por Pierre Bourdieu (Bourdieu, 1998). Este mostra como a educação não só não é neutra, mas traz consigo uma dimensão de sustentação das relações de poder estabilizadas e institucionalizadas em toda a sociedade. Bourdieu (1998) abordará as formas como a escola contribui para a conservação dessas relações. Neste sentido, conservação é entendida de modo diferenciado de Arendt (2001) - para a qual é fundamental a escola ser conservadora, tomando aí um aspecto positivo.

Para Bourdieu (1998), a escola é um mecanismo que perpetua as relações de poder e serve, dentro de um mecanismo maior de transmissão de capital cultural, social 
e econômico, para manutenção das elites e para reforço do poder estabelecido, entre as gerações. Ao mesmo tempo, ela pode significar uma brecha para que indivíduos que não são oriundos das classes dominantes alcancem outra posição social - esta possibilidade é rarefeita, diante da intrincada rede de relações para manutenção intergeracional do poder, da qual a escola constitui um de seus aparelhamentos. Neste sentido, Bourdieu é um crítico do otimismo pedagógico, derrubando toda e qualquer pretensão de neutralidade dessa apresentação da criança ao mundo adulto, conforme seria o objetivo da educação posto por Arendt (2001).

A crise na educação é percebida de modo geral, porém vivenciada de modo diferenciado pelos diversos sujeitos. As desigualdades de acesso ao poder (se) refletem (n)os fatores extra-escolares no tocante à produção de resultados escolares - ou seja, no cumprimento da função da escola. Esta retroalimentação da distribuição social do poder, que se vale também da educação em seu exercício de sustentabilidade, expõe a escola enquanto instituição que mantém e legitima privilégios, portanto, poderes.

As (des)vantagens oriundas do exercício do poder que vão se acumulando intergeracionalmente, tendo a escola como um de seus instrumentos, não se revertem simplesmente pelo fato de haver maiores esforços pela universalização da educação. Pelo contrário, a forma como esta universalização se dá normalmente está mais atrelada a uma demografização (simples elevação do número de pessoas que passam pelos sistemas de ensino) do que a uma democratização da educação - ou seja, uma transformação do papel social da educação que demanda real igualdade de oportunidades e justiça social veraz. Neste cenário perpetuador dessa distribuição social do poder, cabe refletir sobre o real papel exercido pelo professor, bem como sua legitimidade para fazê-lo.

\section{AUTORIDADE DOCENTE: SENSO COMUM E COMPREENSÃO CRÍTICA}

Vitor Paro (Paro, 2010) retoma as discussões de Stoppino (2007a;2007b) e de Arendt (2001) para pensar a educação como exercício de poder. Ele inicia o texto problematizando a visão do senso comum sobre educação e ensino. Esta visão se aproxima, em um determinado grau, do colocado por Arendt (2001): a importância de o professor transmitir conteúdos curriculares para os alunos. No entender de Paro (2010), a educação tem como objetivo a formação do homem em sua integralidade. A educação atualiza histórico-culturalmente o homem, a partir de sua condição de sujeito. Neste sentido, há uma dimensão de progressão similar à de Arendt (2001), mas que se 
concentra na questão histórica, enquanto Arendt enfoca o desenvolvimento mais no sentido biológico e psicossocial. Grosso modo, para Arendt, a função da educação é inserir a criança no mundo adulto, enquanto para Paro a função da educação é inserir o sujeito na história reafirmando-o como sujeito.

Como Paro (2010) enfatiza que o objetivo da educação, para ser efetivo, deve romper com o tradicional e se voltar para uma educação 'democrática', ele vê a necessidade de participação ativa do educando. Esta participação irá se aproximar da forma como Stoppino (2007a ; 2007b) trata da interação entre sujeitos nas relações de poder, diferindo do reforço da autoridade do professor adulto sobre o aluno criança (Arendt, 2001) e também da visão de uma rede de relações de poder disciplinar que adestra o aluno, acima do comportamento de um determinado professor (o qual também estará envolvido nesta rede), conforme Foucault (2000;2013).

Conforme Paro, "o educando só aprende se quiser" (Paro, 2010, p. 30). O aluno é visto como detentor de vontade, como autor, por isso há necessidade de motiválo para desejar a aprendizagem, considerando-o enquanto sujeito. Isto difere do pensamento de Arendt (2001), que considera perniciosa uma suposta autonomia da criança e tentativas de fazer suas vontades. Por outro lado, Paro (2010) também não considera alguns mecanismos operatórios que funcionam sutil e invisivelmente, dentro e fora da escola, produzindo esta indução à aprendizagem, na forma de micro-poderes, como bem destacado por Foucault (2000;2013). Paro defenderá esta indução motivacional para além dos mecanismos de coação presentes no ambiente escolar (prêmio e punição), tornando esta motivação intrínseca ao aluno e provocando resposta positiva aos propósitos educativos do professor. Para tal, será exigida do professor a capacidade de persuasão - o que põe em cheque a questão da autoridade conteudista e suas naturais consequências em termos de aprendizagem.

Diferindo de Arendt (2001), Paro (2010) destaca a importância crucial da persuasão para uma educação democrática - sendo a única forma de processo pedagógico que se pode imaginar para este tipo de educação. Para ele, a persuasão pressupõe ausência de conflito (diferindo, assim, da coerção e da manipulação). Ela supõe um diálogo entre dois atores exercendo sua condição de sujeitos. Ambos exercem poder, constituindo relação de mão dupla, onde cada um pode agir e pode mudar o comportamento do outro, em determinado grau. Esta análise não considera uma série de mecanismos subterrâneos que atuam no processo escolar. Os micro-poderes não são adequadamente enxergados nesta proposta.

Por outro lado, Paro (2010) chama a atenção para uma questão não problematizada por Arendt (2001): a 
diversidade. As condições de existência dos alunos devem ser levadas em conta quando da reflexão sobre a função da educação e da aprendizagem por parte desses alunos. Isto coloca um desafio e uma responsabilidade sobre o professor, que vai além de ser coletivamente responsável pelo mundo que aí está. Paro (2010) coloca sobre a figura do professor a necessidade de querer ensinar, de propiciar condições para que os alunos sejam sujeitos, de se comprometer com o trabalho pedagógico, de saber como ensinar para alcançar a formação da personalidade desse aluno e ter consciência política de sua função no tocante à democracia e à formação cidadã. Tudo isto compõe um fardo que tem tornado pesado o ofício do magistério. Pereira et al. (2011) exemplifica este peso com análise de depoimento de professores.

Pereira et al. (2011) chama a atenção para aspectos não identificados por Arendt (2001), principalmente no tocante à função do professor. Não basta discutir crise de autoridade baseada em tradição. As visões de autoridade, de respeito e de funções e sentidos da educação estão fragmentadas, variantes e não suportam mais um tipo idealizadoderelaçãoentreprofessor, alunoesaber.Omodelo de professor, ator-modelo, com roteiro já pré-testado, que atua para uma plateia homogênea e receptiva não tem espaço na escola atual - se é que já existiu algum dia, livre dos mecanismos de adestramento. A falência do modelo tradicional de verbalização, o ritual de desqualificação pelo qual os professores passam, as incertezas e fragilidades da profissão, as exaustões do tempo e defasagem acelerada dos conteúdos, a desautorização docente, dentre outras características atuais da educação, colocam em cheque o modelo educativo que se pratica nas escolas, provocando a derrocada de certezas tradicionais no mundo escolar.

As relações entre poder e saber, no âmbito escolar, devem ser repensadas, à luz de um currículo que, mesmo que seja mais ensinado por professores conteudistas (como pleiteou Arendt, 2001), não apresenta aderência ao cotidiano das diversas crianças, adolescentes e jovens que frequentam o mundo escolar. Neste sentido, Pereira et al. (2011) avançam na discussão sobre diversidade, apontada por Paro (2010), ampliando-a e aprofundando-a. Quais são os saberes úteis à sociedade? Quem deve responder a esta pergunta? Quem pode, realmente, responder a esta pergunta?

Os professores estão sensibilizados pelas transformações da sociedade como um todo e empenhados no incremento de iniciativas em direção à promoção da igualdade. Contudo, muitos parecem não estar dispostos a abdicar de suas prerrogativas tradicionais de saber, nem de sua posição e status que querem assegurar a todo custo, ainda que isso lhes escorra das mãos. (Pereira et al., 2011, p. 17, grifo no original). 
As desmotivações dos professores aliadas a uma burocracia ingressante no sistema escolar e a uma defasagem em termos de novas tecnologias de informação e comunicação provocam um mal-estar que se alastra nesse sistema. Romper isso é exigido do professor enquanto indivíduo, cobrando-se dele a auto-motivação, baseada em sua própria experiência de vida e sem apoio formativo adequado. A resposta a esta situação envolve elevação da profissionalização do professor, mas este movimento, por outro lado, tem repercutido de forma não totalmente positiva, produzindo perda de prestígio social deste mesmo professor.

A instituição disciplinar não está mais funcionando como os professores esperavam. Os choques geracionais e a entrada de uma massa heterogênea na escola têm provocado assincronia nos ajustes e repercutido na eficácia da produção de corpos dóceis. O sistema escolar permanece pressupondo um aluno padrão e não conseguindo dar conta daqueles que são estranhos à norma. Os professores, muitas vezes, tomam este estranho como causador de desautorização. O realismo conservador entranhado no sistema escolar se choca com a realidade. A resposta pensada a isso, por vezes, tem sido um idealismo ingênuo, que não produz mudança, mas frustra expectativas tanto de professores quanto de alunos. A tentativa de ignorar as diferenças entre o aluno-padrão e os diversos alunos reais que a escola recebe tem sido penosa e danosa. Tentar evitar o confronto e a tensão da relação com estes sujeitos, ou tratá-los como se não fossem diferentes é provocar e alimentar crises na educação e a partir da educação.

Pereira et al (2011) exemplificam como os professores se sentem na tentativa de persuadir os alunos em prol da aprendizagem, conforme sugerido por Paro (2010), mas os alunos nãotêm respondidoà altura eentradonojogo da escola atraente - seja evadindo, afrontando ou ficando apático. Muitos alunos fazem questão de não estar interessados em uma escola muito lenta na tentativa de acompanhar as aceleradas modificações da sociedade. As relações de poder dentro da arena escolar terminam, de modo reducionista e pragmático, enfocando negociações constantes entre professores e alunos para que minimamente ocorram as aulas. Os mecanismos dialogais postos em prática são elaborados a partir das vivências e buscam seduzir os alunos, em uma tentativa de gerar empatia, mas também de reforçar o lugar do professor na hierarquia educacional. Ou seja, são novas formas empíricas de garantir o saber-poder dos professores frente à realidade em crise no ambiente escolar, refazendo uma posição de controle do professor, do ponto de vista hierárquico, produzindo poder epistemológico. Em última instância, esses mesmos professores, por vezes, retomam velhas ferramentas de controle e dominação punição, indiferença, discursos autoritários, moralistas, entre outras. 
Por fim, imersos nas lutas pela manutenção dos mecanismos de saber-poder, os professores vão (re) construindo seu fazer docente e sua própria imagem como docente. As relações entre educação e poder são processadas de formas subjetivas, contribuindo para um percurso docente que refaça o sentido do exercício da profissão, a função de educar e o convencimento de sua contribuição pessoal para a formação dos alunos. Isso permite ao professor se reconhecer socialmente como tal e reafirma a singularidade de sua identidade de professor.

\section{CONSIDERAÇÕES FINAIS}

De acordo com o exposto, chama a atenção a forma como as releituras e críticas ao pensamento sobre educação e poder podem variar, conforme o ponto de vista dos autorese das áreas de saber consideradas envolvendo desde discussões sobre formação do sujeito até práticas cotidianas no ambiente escolar. Com isso, pode ser percebida a forma como as reflexões sobre as relações entre educação e poder são matizadas. Todavia, para que adequadamente respaldem uma discussão contemporânea sobre a escola, estas reflexões precisam estar contextualizadas, ou seja, necessitam considerar as mudanças na sociedade, nas formas de relacionamento e de saber, bem como apreender adequadamente os processos de massificação e de revoluções tecnológicas, em suas imbricações sobre e com os mecanismos de poder.

As formas das relações sociais mudaram não apenas do ponto de vista tecnológico, mas alterações maiores se deram do ponto de vista sociocultural, trazendo implicações mais profundas para a perspectiva de compreensão dos acontecimentos e de suas motivações. Constatar a crise na educação já não é mais satisfatório, do ponto de vista de uma análise da autoridade docente. Serão necessários mais trabalhos de pesquisa que sejam multidisciplinares e que dêem conta de acurar os diagnósticos, considerando os diversos sujeitos envolvidos no processo, abrindo espaços para que estes sujeitos falem, e alterando metodologicamente os procedimentos de pesquisa para que essas vozes sejam escutadas a partir de sua realidade, por si mesmas. Há muita gente falando sobre como os professores devem solucionar os seus problemas. Receitas não faltam. O que carecemos hoje é de espaços de diálogo republicanos e democráticos, que consigam avançar para além de escutas públicas que sejam meras legitimadoras de decisões unilaterais já previamente tomadas pelos detentores do poder oficial - seja no âmbito da sala, da escola, da rede de ensino ou das políticas e programas governamentais. 
Para melhor compreender a crise de autoridade docente se faz necessário maior compreensão da educação, da(s) sociedade(s) e da própria crise de poder que esta vivencia contemporaneamente. $\mathrm{O}$ modo como a sociedade funciona e se (auto)regula remete às questões relativas ao exercício do poder e implica em tratar dialogicamente as perguntas estruturantes (o que é educação, para que serve etc.), ao mesmo tempo em que se reflete sobre quais respostas os sujeitos que nela estão (in)diretamente envolvidos têm como expectativas, bem como, enquanto motivações para suas (re)ações. Esteé um debate que quanto mais se intensifica, mais dá a perceber a necessidade de um mergulho profundo, ao mesmo tempo em que demanda acurar um olhar holístico, que abranja o todo a partir das partes, em uma visão complexa da vida em sociedade, do sentido e do lugar da educação e da questão do sujeito e de suas interações.

\section{REFERÊNCIAS}

ARENDT, Hannah. Entre o passado e o futuro. Trad. Mauro W. Barbosa. São Paulo:

Perspectiva, 2001.

BOURDIEU, Pierre. Escritos de Educação.Maria Alice Nogueira e Afrânio Catani (orgs.). Petrópolis: Vozes, 1998.

FOUCAULT, Michel. Microfísica do Poder. Org. e Trad. Roberto Machado. Rio de Janeiro: Graal, 2000.

FOUCAULT, Michel. Vigiar e punir: nascimento da prisão.Trad. Raquel Ramalhete. Petrópolis: Vozes, 2013.

PARO, Vitor Henrique. Educação como Exercício do Poder:crítica ao senso comum em educação. São Paulo: Cortez, 2010.

PEREIRA, Marcelo Ricardo, PAULINO, Bárbara Oliveira e FRANCO, Raquel Braga.Acabou a autoridade? Professor, subjetividade e sintoma. Belo Horizonte: Fino Traço, 2011

STOPPINO, Mario. Autoridade. In: BOBBIO, Norberto; MATTEUCCI, Nicola; PASQUINO, Gianfranco. Dicionário de Política. Trad. João Ferreira et al. Vol. 1. Brasília: UnB, 2007a. P. 88-94.

STOPPINO, Mario. Poder. In: BOBBIO, Norberto, MATTEUCCI, Nicola e PASQUINO, Gianfranco. Dicionário de Política. Trad. João Ferreiraet al.Vol. 1. Brasília: UnB, 2007b. P. 933-943. 